\title{
Effect of Sodium Selenite on Lipid Peroxidation and Glutathione in Alloxan Induced Diabetic Rats
}

\author{
Hassan Ahmadvand ${ }^{1, *} ;$ Ali Khosrowbeygi ${ }^{1}$ \\ ${ }^{1}$ Department of Biochemistry, Lorestan University of Medical Sciences, Khorramabad, IR Iran \\ *Corresponding author: Hassan Ahmadvand, E-mail: hassan_a46@yahoo.com \\ Received: January 15, 2014; Accepted: April 15, 2014
}

\begin{abstract}
Background: Diabetes-related dysfunctions are the major causes of mortality and morbidity for diabetic patients.
Objectives: Selenium is a potent antioxidant. In the present study, we examined antioxidative activities of sodium selenite and possible protective effect of it on serum, liver and kidney lipid peroxidation and glutathione in alloxan-induced type 1 diabetic rats.

Materials and Methods: In this experimental study 40 Sprage Dawley male rats were divided into 4 groups randomly; group I as control, group II as sham treated with sodium selenite (1 mg/kg i.p. daily), group III as diabetic untreated, and group IV as diabetic treated with sodium selenite $(1 \mathrm{mg} / \mathrm{kg}$ i.p. daily) after induce diabetes, respectively. Diabetes was induced in the 3rd and 4th groups by alloxan injection (s.c.). After 8 weeks, animals were anaesthetized, liver and kidney were then removed immediately and used fresh or kept frozen until analysis. Blood samples were also collected before killing of the rats to measure the lipid peroxidation and glutathione level.

Results: Liver and kidney content of lipid peroxidation decreased in diabetic treated group compared with untreated group. Kidney content of glutathione significantly increased in diabetic treated group compared with untreated group. Serum level of glutathione and liver content of it slightly increased in diabetic treated group compared with untreated group.

Conclusions: This study showed that sodium selenite might be a potent antioxidant and exert beneficial effects on the lipid peroxidation and glutathione in alloxan-induced type 1 diabetic rats.
\end{abstract}

Keywords:Diabetes Mellitus; Lipid Peroxidation; Rats; Sodium Selenite; Glutathione

\section{Background}

Diabetes-related dysfunctions are the major causes of mortality and morbidity for diabetic patients (1). Although the precise mechanism by which hyperglycemia induces organ dysfunction is not fully understood, one of the hypothesis to explain this phenomenon is mainly focused on the role of free radicals in these disease states (2). Under physiological conditions, hydrogen peroxide, superoxide and hydroxyl radicals, collectively called reactive oxygen species, are continuously produced and kept under strict control by many enzymes and antioxidants within the cells (3). However, when the finely balanced equilibrium between free radical production and cellular antioxidant defenses is shifted in favor of more free radical production collectively called oxidative stress; this can promote cellular injury $(4,5)$. Clinical and experimental studies have shown that disturbing of oxidant-antioxidant balance system is involved in the pathogenesis of chronic diseases such as cancer (6), coronary heart disease $(7,8)$, diabetes and many diabetic complications (9).

A number of natural antioxidant such as vitamin E, coenzyme Q10 and phenolic compounds are known to have hypoglycemic, hypolipidemic and protection of altered antioxidant enzymes and lipid peroxidation in vivo (10).
Chemical drugs have many side effects; therefore, looking for new antidiabetic drugs from natural antioxidants sources is still attractive because they are safe and good alternative for treatment of diabetes mellitus. A growing body of research indicates that nutritional deficiencies of antioxidants contribute to the development of diabetes $(11,12)$. Among antioxidant micronutrients, selenium (Se) is an essential dietary trace element, which plays an important role in a number of biological processes in humans and other species (13). Deficiency of this element induces some pathological conditions, such as cancer, coronary heart disease, and liver necrosis (14-16). Researchers have shown selenium and zinc efficacy on immune system and increase response to influenza and HBV vaccine (17). Also researchers have shown sodium selenite decrease levels of lipid peroxidation (LPO) and NOPs (nitric oxide products) and increase activities of superoxide dismutase, GR (glutathione reductase), and GPX (glutathione peroxidase) in heart diabetes-induced rats (18). Selenium is an essential component of several enzymes such as GPX, TR (thioredoxin reductase) and SeP (selenoprotein P), which contains Seas selenocysteine (19). Various organic and inorganic Se compounds, generally considered to be antioxidants, produced mixed

Copyright (c) 2015, Zahedan University of Medical Sciences. This is an open-access article distributed under the terms of the Creative Commons Attribution-NonCommercial 4.0 International License (http://creativecommons.org/licenses/by-nc/4.0/) which permits copy and redistribute the material just in noncommercial usages, provided the original work is properly cited. 
results when tested in animal models and human subjects (20). Among them, sodium selenite has been shown to be most effective in both in vitro and in vivo (20). The possible protective effects of sodium selenite on serum, kidney and liver lipid peroxidation status and glutathione in alloxan-induced type 1 diabetic rats have not been reported yet.

\section{Objectives}

Therefore, a study was designed to investigate amelioration of altered serum, kidney and liver lipid peroxidation status and glutathione by sodium selenite in alloxan-induced type 1 diabetic rats.

\section{Materials and Methods}

\subsection{Animals}

In this experimental study 40 male mature SpragueDawley rats (180-200 g) were obtained from Pasteur Institute of Tehran and were allowed to adapt themselves with the new location for one week. They were kept under standard conditions and were fed a standard rat chow and drinking water ad libitum throughout the study period. This study was approved by the Animal Ethics Committee of the Medical University of Lorestan with accordance to the national health and medical research council guidelines. The rats were divided into four groups (10 per each). The studied groups were as follows: group I as control, group II as sham treated with sodium selenite by $1 \mathrm{mg} / \mathrm{kg}$ i.p daily, group III as diabetic without treatment and the group IV as diabetic treatment with sodium selenite.

\subsection{Chemicals}

Sodium selenite, sodium chloride $(\mathrm{NaCl})$, disodium hydrogen phosphate (Na2HPO4) and trichloroacetic acid were purchased from Sigma-Aldrich (St. Louis, MO, USA). All solvents used were of analytical grade. 2-thiobarbituric acid (TBA) was obtained from Fluka Chemie (Buchs SG, Switzerland).

\subsection{Diabetes Induction}

Diabetes was induced after overnight fasting in the second and third groups by injection of alloxan monohydrate $(120 \mathrm{mg} / \mathrm{kg}$ ) subcutaneously (21). Beta cell degradation by alloxan leads to release of more insulin. Because of acute hypoglycemia, the rats received $10 \%$ sucrose solution for $48 \mathrm{~h}$ instead of drinking water. Five days after induction of diabetes, blood samples were gathered from the end part of tails. Blood glucose was measured by glucometer and the rats with blood glucose level of $\geq 300$ $\mathrm{mg} / \mathrm{dL}(16.7 \mathrm{mM} / \mathrm{L})$ were considered as diabetic $(22,23)$. During the first five days after diabetes induction, 1-3 rats per group died because of alloxan toxicity. The rats were kept at 12:12 h dark-light period in $21 \pm 3^{\circ} \mathrm{C}$ temperature.
All animals were allowed free access to food and water ad libitum during the experiment. The third group was treated with sodium selenite by $1 \mathrm{mg} / \mathrm{kg}$ i.p. daily (24). The treatment was begun at the first day of diabetes induction. After 8 weeks treatment, animals were anesthetized (Nesdonal $50 \mathrm{mg} / \mathrm{kg}$, i.p.), blood samples were obtained from hearts and allowed to clot for $20 \mathrm{~min}$ in laboratory temperature and then centrifuged at $3000 \mathrm{rpm}$ for 10 min for serum separation (21). Liver and kidneys of the rats were also removed immediately and used fresh or kept frozen until the analysis.

\subsection{Levels of Malonedialdehyde (MDA)}

Serum, liver, and kidney contents of MDA, as a product of lipid peroxidation, were measured by the thiobarbituric acid (TBA) assay. Liver and kidney contents of MDA were also analyzed, using a Shimadzu spectrophotometer (Tokyo, Japan) (25).

\subsection{Levels of Glutathione (GSH)}

Serum liver and kidney contents of GSH were assayed spectrophotometrically at $412 \mathrm{~nm}$, according to the method of Ellman, using a Shimadzu spectrophotometer (Tokyo, Japan). The contents of GSH were expressed as $\mathrm{mM} / \mathrm{mg}$-pr (26). All values are expressed as mean \pm SD. The data were compared between groups by Mann-whitney U test. Statistical analyses were performed using the SPSS13 for windows software. A p-value $<0.05$ was considered statistically significant.

\section{Results}

Effect of sodium selenite on serum, kidney and liver MDA level of diabetic rats: The levels of MDA in serum, kidney and liver are shown in Table 1 . The level of serum MDA in the untreated diabetic rats was significantly (1.6fold) higher than that of control animals. The level of MDA in the serum of diabetic rats treated with sodium selenite was very low, similar to the level found in the control animals. The treatment of diabetic animal with sodium selenite could significantly (31.24\%) inhibit the elevation of MDA in comparison with the untreated diabetic animals.

The level of kidney MDA in the untreated diabetic rats was significantly (1.65-fold) higher than that of control animals. The treatment of diabetic animal with sodium selenite could significantly $(27.25 \%)$ inhibit the increase of MDA in comparison with the untreated diabetic animals. The level of liver MDA in the untreated diabetic rats was significantly (1.61-fold) higher than that of control animals. The treatment of diabetic animal with sodium selenite could (31.25\%) inhibit the increasing of MDA in comparison with the untreated diabetic animals, but it was not statistically significant. The level of MDA in the serum, renal and liver of sham rats treated with sodium selenite were low, similar to the level found in the control animals. 
Ahmadvand H et al.

Table 1. The Effect of Sodium Selenite on Serum, Liver and Kidney MDA Content in Alloxan Induced Diabetic rats a,b

\begin{tabular}{lccc}
\hline MDA, nM/mg protein & Serum & Kidney & Liver \\
\hline Control & $89.36 \pm 23.48$ & $91.93 \pm 18.88^{\mathrm{C}}$ & $95.19 \pm 25.01^{\mathrm{C}}$ \\
Sham & $106.69 \pm 33.39$ & $97.77 \pm 15.29^{\mathrm{C}}$ & $113.65 \pm 35.57^{\mathrm{C}}$ \\
Diabetic & $144.20 \pm 32.68^{\mathrm{C}}$ & $151.54 \pm 30.12$ & $153.61 \pm 34.81$ \\
Diabetic treated & $99.15 \pm 17.66^{\mathrm{d}}$ & $110.24 \pm 30.84^{\mathrm{C}}$ & $105.61 \pm 18.82^{\mathrm{C}}$ \\
\hline
\end{tabular}

a Abbreviation: MDA, malonedialdehyde.

$\mathrm{b}$ Values represented as mean \pm SD.

${ }^{c} \mathrm{P}<0.05$ as compared with control group.

$\mathrm{d} \mathrm{P}<0.05$ as compared with diabetic without treatment group.

Table 2. The Effect of Sodium Selenite on Serum, Liver and Kidney GSH Content in Alloxan Induced Diabetic rats ${ }^{\mathrm{a}, \mathrm{b}}$

\begin{tabular}{|c|c|c|c|}
\hline GSH, nM/mg Protein & Serum & Kidney & Liver \\
\hline Control & $12.63 \pm 1.64^{\mathrm{C}}$ & $10.58 \pm 3.62^{c}$ & $12.63 \pm 1.64^{\mathrm{C}}$ \\
\hline Sham & $10.00 \pm 1.42^{\mathrm{c}, \mathrm{d}}$ & $8.25 \pm 1.01^{c, d}$ & $10.00 \pm 1.42^{d}$ \\
\hline Diabetic & $6.87 \pm 1.86$ & $5.21 \pm 0.74$ & $9.03 \pm 1.71$ \\
\hline Diabetic treated & $7.97 \pm 1.62^{d}$ & $6.74 \pm 1.48^{c, d}$ & $7.97 \pm 1.62^{d}$ \\
\hline $\begin{array}{l}\text { a Abbreviation: GSH, Gluta } \\
\text { b Values represented as m } \\
\text { c } \mathrm{P}<0.05 \text { as compared wi } \\
\text { d } \mathrm{P}<0.05 \text { as compared wi }\end{array}$ & eatment group. & & \\
\hline
\end{tabular}

Effect of sodium selenite on serum, kidney and liver GSH level of diabetic rat: The levels of GSH in serum, kidney and liver are shown in Table 2. The level of serum GSH in the untreated diabetic rats was significantly (1.84-fold) lower than that of control animals. The treatment of diabetic animal with sodium selenite could slightly increase of GSH in comparison with the untreated diabetic animals. The level of renal GSH in the untreated diabetic rats was significantly (2.03-fold) lower than that of control animals. The sodium selenite treated diabetic animals showed significantly elevation (29.36\%) in GSH level compared with the untreated animals. The level of liver GSH in the untreated diabetic rats was significantly (1.39-fold) lower than that of control animals.

The treatment of diabetic animal with sodium selenite could not increase (5.43\%) in GSH level compared with the untreated samples. The level of GSH in the serum, renal and liver of sham rats treated with sodium selenite was high, similar to the level found in the control animals.

\section{Discussion}

This study showed that sodium selenite increased serum, renal and liver glutathione and decreased lipid peroxidation in alloxan induced diabetic rats. There is much evidence that oxidative stress play a key role in the most pathogenic pathway of diabetic injuries. Free radicals such as superoxide can induce cell and tissue injuries lipid peroxidation and increase carcinogenesis, inflammation, early aging, cardiovascular diseases and tissue damage in diabetes $(27,28)$. Also, studies showed that using organic selenium have protective effects on lipid peroxidation in chicken blood during fattening and after fast- ing. Other study showed that using selenium have protective effects on lipid peroxidation in alloxan induced toxicity rats $(29,30)$. Antioxidants such as selenium, vitamin E, coenzyme Q10 protect the cells against oxidative stress mediated cellular injuries by converting the toxic free radicals to non-toxic products $(17,29,31)$. Therefore use of antioxidant as complementary therapy is useful for diseases that related to oxidative stress. Diabetic animals showed significantly increasing in serum, liver and kidney lipid peroxidation compared with the control group. Treatment of diabetic animals with sodium selenite significantly inhibited increasing of serum and kidney lipid peroxidation in comparison with the untreated diabetic animals. Previous studies showed that using natural antioxidants supplements such as vitamin E (32), -lipoic acid (33), flavonoids (34), oleanolic acid (35), selenium (36), vanadium, -carotene, zinc, vitamin C $(37,38)$, aminoguanidine (39), lycopene (40) and natural phenolic compounds have protective effects on lipid peroxidation in diabetics and chronic disease (41). Several reports showed that selenium has neuroprotective effect and in cerebral ischemia and improves antioxidant capacity in vitro and in vivo in patients with coronary artery disease $(42,43)$. The protective role of selenium administration against oxidized low density lipoprotein and antioxidant defense in diabetic rats was reported (44). Also, selenium decrease lipid peroxidation and ameliorate oxidative stress in liver and kidneys from Cd-induced oxidative damage (45). Therefore, selenium might be useful as a natural antioxidant for reducing or preventing the complications that related to oxidative stress in diabetes patients. Results of the present study are in accordance with 
others showing that sodium selenite can increase GSH level and decrease lipid peroxidation. Therefore, sodium selenite as a natural antioxidant with beneficial effects on GSH level and lipid peroxidation might be helpful in reducing the complications of different tissue damages seen in diabetic patients. Antioxidant therapy is one of the most important treatment strategies in diabetic patients for prevention and slowing of diabetic complications progression such as hyperglycemia, hyperlipemia, hepatic damage, and nephropathy (11). Although the detailed mechanisms of sodium selenite antioxidant function cannot be fully explained by our results, several studies have explained some mechanisms of sodium selenite antioxidant function. Sodium selenite may directly eliminate free radicals in vitro. Therefore, sodium selenite as a good antioxidant with multi-beneficial properties could be proposed as a supplement in diabetic patients without diabetic nephropathy for prevention of its.

This study showed that sodium selenite possess a good antioxidant activity and has beneficial effects, in increasing the reduced serum, renal and liver antioxidant enzymes and GSH levels in alloxan-induced-diabetic rats. Hence, attenuation of lipid peroxidation level and elevation of antioxidant enzymes activities can decrease diabetic complication such as nephropathy in diabetic patients.

\section{Acknowledgements}

This research project's costs are provided by the Dr Hassan Ahmadvand. Research proposal Act number of 1796 at Lorestan University of Medical Sciences.

\section{Authors' Contributions}

All authors had equal role in design, work, statistical analysis, and manuscript writing.

\section{Funding/Support}

Lorestan University of Medical Sciences has been supported this study.

\section{References}

1. Tsur A, Volpin G. Re-amputations and mortality among patients with diabetic or peripheral vascular complications. Isr Med Assoc J. 2014;16(2):115-6.

2. Lucchesi AN, Freitas NT, Cassettari LL, Marques SF, Spadella CT. Diabetes mellitus triggers oxidative stress in the liver of alloxantreated rats: a mechanism for diabetic chronic liver disease. Acta Cir Bras. 2013;28(7):502-8

3. Sueishi Y, Hori M, Ishikawa M, Matsu-Ura K, Kamogawa E, Honda Y, et al. Scavenging rate constants of hydrophilic antioxidants against multiple reactive oxygen species. J Clin Biochem Nutr. 2014;54(2):67-74

4. Singal PK, Bello-Klein A, Farahmand F, Sandhawalia V. Oxidative stress and functional deficit in diabetic cardiomyopathy. Adv Exp Med Biol. 2001;498:213-20.

5. Touyz RM. Reactive oxygen species in vascular biology: role in arterial hypertension. Expert Rev Cardiovasc Ther. 2003;1(1):91-106.

6. Gupta RK, Patel AK, Kumari R, Chugh S, Shrivastav C, Mehra S, et al. Interactions between oxidative stress, lipid profile and anti- oxidants in breast cancer: a case control study. Asian Pac J Cancer Prev. 2012;13(12):6295-8.

7. Vassalle C, Bianchi S, Battaglia D, Landi P, Bianchi F, Carpeggiani C. Elevated levels of oxidative stress as a prognostic predictor of major adverse cardiovascular events in patients with coronary artery disease. J Atheroscler Thromb. 2012;19(8):712-7.

8. Rahsepar AA, Pourghadamyari H, Moohebati M, Parizadeh SM Tavallaie S, Paydar R, et al. Prooxidant-anti-oxidant balance is not associated with extent of coronary artery disease. Clin Biochem. 2011;44(16):1304-8.

9. Tabak O, Gelisgen R, Erman H, Erdenen F, Muderrisoglu C, Aral $\mathrm{H}$, et al. Oxidative lipid, protein, and DNA damage as oxidative stress markers in vascular complications of diabetes mellitus. Clin Invest Med. 2011;34(3):E163-71.

10. Kelkel M, Schumacher M, Dicato M, Diederich M. Antioxidant and anti-proliferative properties of lycopene. Free Radic Res. 2011;45(8):925-40.

11. Zatalia SR, Sanusi H. The role of antioxidants in the pathophysiology, complications, and management of diabetes mellitus. Acta Med Indones. 2013;45(2):141-7.

12. Bonnefont-Rousselot $\mathrm{D}$. The role of antioxidant micronutrients in the prevention of diabetic complications. Treat Endocrinol. 2004;3(1):41-52.

13. Fraga CG. Relevance, essentiality and toxicity of trace elements in human health. Mol Aspects Med. 2005;26(4-5):235-44.

14. Tang J, Tan W, Zhu Y, Wang L, Zhai L. [Effect of selenium on the protection of myocardial cells from injuries induced by overloaded reactive oxygen species, and on the expression of actin in myocardial cells]. Wei Sheng Yan Jiu. 2012;41(1):2-5.

15. Ognjanovic BI, Markovic SD, Pavlovic SZ, Zikic RV, Stajn AS, Saicic ZS. Effect of chronic cadmium exposure on antioxidant defense system in some tissues of rats: protective effect of selenium. Physiol Res. 2008;57(3):403-11.

16. Soudani N, Troudi A, Bouaziz H, Ben Amara I, Boudawara T, Zeghal N. Cardioprotective effects of selenium on chromium (VI)-induced toxicity in female rats. Ecotoxicol Environ Saf. 2011;74(3):513-20.

17. Janbakhsh A, Mansouri F, Vaziri S, Sayad B, Afsharian M, Rahimi $\mathrm{M}$, et al. Effect of selenium on immune response against hepatitis B vaccine with accelerated method in insulin-dependent diabetes mellitus patients. Caspian J Intern Med. 2013;4(1):603-6.

18. Ayaz M, Turan B. Selenium prevents diabetes-induced alterations in $[\mathrm{Zn} 2+] \mathrm{i}$ and metallothionein level of rat heart via restoration of cell redox cycle. Am J Physiol Heart Circ Physiol. 2006;290(3):H1071-80.

19. Suryo Rahmanto A, Pattison DI, Davies MJ. Photo-oxidationinduced inactivation of the selenium-containing protective enzymes thioredoxin reductase and glutathione peroxidase. Free Radic Biol Med. 2012;53(6):1308-16.

20. Combs GJ, Gray WP. Chemopreventive agents: selenium. Pharmacol Ther. 1998;79(3):179-92.

21. Ahmadvand H, Tavafi M, Khosrowbeygi A. Amelioration of altered antioxidant enzymes activity and glomerulosclerosis by coenzyme Q10 in alloxan-induced diabetic rats. J Diabetes Complications. 2012;26(6):476-82.

22. Haidara MA, Mikhailidis DP, Rateb MA, Ahmed ZA, Yassin HZ, Ibrahim IM, et al. Evaluation of the effect of oxidative stress and vitamin E supplementation on renal function in rats with streptozotocin-induced Type 1 diabetes. J Diabetes Complications. 2009;23(2):130-6.

23. Tavafi M, Ahmadvand H, Tamjidipoor A, Delfan B, Khalatbari AR. Satureja khozestanica essential oil ameliorates progression of diabetic nephropathy in uninephrectomized diabetic rats. Tissue Cell. 2011;43(1):45-51.

24. Chakrabarti S, Brodeur J. Influence of selenium on the metabolism of bromobenzene and a possible relationship to its hepatotoxicity. Environ Res. 1985;37(2):327-39.

25. Ohkawa H, Ohishi N, Yagi K. Assay for lipid peroxides in animal tissues by thiobarbituric acid reaction. Anal Biochem. 1979;95(2):351-8.

26. Ellman GL. Tissue sulfhydryl groups. Arch Biochem Biophys. 1959;82(1):70-7. 
27. Marjani A. Lipid peroxidation alterations in type 2 diabetic patients. PakJ Biol Sci. 2010;13(15):723-30.

28. Cuerda C, Luengo LM, Valero MA, Vidal A, Burgos R, Calvo FL, et al. [Antioxidants and diabetes mellitus: review of the evidence]. Nutr Hosp. 2011;26(1):68-78.

29. Pirsljin J, Milinkovic-Tur S, Ljubic BB, Zdelar-Tuk M. The effect of organic selenium supplementation on antioxidative characteristics and lipid peroxidation in chicken blood during fattening and after fasting. Veterinarski arhiv. 2008;78(3):187.

30. Yadav P, Sarkar S, Bhatnagar D. Protective effect of glutathione and selenium against alloxan induced lipid peroxidation and loss of antioxidant enzymes in erythrocytes. $J$ Biosci. 1994;19(1):19-25.

31. Ahmadvand H, Mabuchi H, Nohara A, Kobayahi J, Kawashiri MA. Effects of coenzyme Q(10) on LDL oxidation in vitro. Acta Med Iran. 2013;51(1):12-8.

32. Goldenstein H, Levy NS, Lipener YT, Levy AP. Patient selection and vitamin E treatment in diabetes mellitus. Expert Rev Cardiovasc Ther. 2013;11(3):319-26.

33. Rochette L, Ghibu S, Richard C, Zeller M, Cottin Y, Vergely C. Direct and indirect antioxidant properties of alpha-lipoic acid and therapeutic potential. Mol Nutr Food Res. 2013;57(1):114-25.

34. van Dam RM, Naidoo N, Landberg R. Dietary flavonoids and the development of type 2 diabetes and cardiovascular diseases: review of recent findings. Curr Opin Lipidol. 2013;24(1):25-33.

35. Castellano JM, Guinda A, Delgado T, Rada M, Cayuela JA. Biochemical basis of the antidiabetic activity of oleanolic acid and related pentacyclic triterpenes. Diabetes. 2013;62(6):1791-9.

36. Rocourt CR, Cheng WH. Selenium supranutrition: are the potential benefits of chemoprevention outweighed by the promotion of diabetes and insulin resistance? Nutrients. 2013;5(4):1349-65.

37. Smith DM, Pickering RM, Lewith GT. A systematic review of vana- dium oral supplements for glycaemic control in type 2 diabetes mellitus. QJM. 2008;101(5):351-8.

38. Rossoni-Junior JV, Araujo GR, Padua Bda C, Chaves MM, Pedrosa ML, Silva ME, et al. Annato extract and beta-carotene modulate the production of reactive oxygen species/nitric oxide in neutrophils from diabetic rats. J Clin Biochem Nutr. 2012;50(3):177-83.

39. Di Naso FC, Forgiarini Junior LA, Forgiarini LF, Porawski M, Dias AS, Marroni NA. Aminoguanidine reduces oxidative stress and structural lung changes in experimental diabetes mellitus.J Bras Pneumol. 2010;36(4):485-9.

40. Bose KS, Agrawal BK. Effect of lycopene from tomatoes (cooked) on plasma antioxidant enzymes, lipid peroxidation rate and lipid profile in grade-I hypertension. Ann Nutr Metab. 2007;51(5):477-81.

41. Kaliora AC, Dedoussis GV. Natural antioxidant compounds in risk factors for CVD. Pharmacol Res. 2007;56(2):99-109.

42. Ahmad A, Khan MM, Ishrat T, Khan MB, Khuwaja G, Raza SS, et al Synergistic effect of selenium and melatonin on neuroprotection in cerebral ischemia in rats. Biol Trace Elem Res. 2011;139(1):81-96.

43. Schnabel R, Lubos E, Messow CM, Sinning CR, Zeller T, Wild PS, et al. Selenium supplementation improves antioxidant capacity in vitro and in vivo in patients with coronary artery disease The SElenium Therapy in Coronary Artery disease Patients (SETCAP) Study. Am Heart J. 2008;156(6):1201 e1-11.

44. Ghaffari T, Nouri M, Irannejad E, Rashidi MR. Effect of vitamin e and selenium supplement on paraoxonase-1 activity, oxidized low density lipoprotein and antioxidant defense in diabetic rats. Bioimpacts. 2011;1(2):121-8.

45. Chen X, Zhu YH, Cheng XY, Zhang ZW, Xu SW. The protection of selenium against cadmium-induced cytotoxicity via the heat shock protein pathway in chicken splenic lymphocytes. Molecules. 2012;17(12):14565-72. 